\title{
Why the Fluid Friction Factor should be Abandoned, and the Moody Chart Transformed
}

\author{
Eugene F. Adiutori* \\ Ventuno Press, Green Valley, Arizona
}

\begin{abstract}
The "fluid friction factor" (f) should be abandoned because it is a mathematically undesirable parameter that complicates the solution of fluid flow problems.

$\mathrm{f}$ is the dimensionless group $\pi^{2} \mathrm{~g} \rho \Delta \mathrm{PD}^{5} / 8 \mathrm{LW}^{2}$. This group is mathematically undesirable because it includes $\Delta \mathrm{P}, \mathrm{W}$, and $\mathrm{D}$. Therefore if $\mathrm{f}$ is used in the solution of a problem, the problem must be solved with $\Delta \mathrm{P}, \mathrm{W}$, and $\mathrm{D}$ in the same term, even though fluid flow problems are generally much easier to solve if $\Delta \mathrm{P}, \mathrm{W}$, and $\mathrm{D}$ are in separate terms. (Just as it is generally much easier to solve equations if $\mathrm{x}$ and $\mathrm{y}$ are in separate terms).

The mathematical complication introduced by $\mathrm{f}$ is illustrated by the Moody chart (Fig. 1). Because the chart is based on $\mathrm{f}$, it must be read iteratively (or by trial-and-error) to determine $\mathrm{W}$ or D. But if the Moody chart is transformed in order to eliminate $\mathrm{f}$, the transformed chart (Fig. 2) is read directly to determine $\Delta \mathrm{P}, \mathrm{W}$, or $\mathrm{D}$.

The fluid flow methodology described herein altogether abandons f, and allows fluid flow problems to be solved in the simplest possible manner.
\end{abstract}

\section{INTRODUCTION}

In the modern view, fluid flow behavior is described by the "Darcy equation" (also known as the "Darcy-Weisbach equation"), Expression (1). In the laminar regime, $f$ is described by Eq. (2). In the turbulent regime, $\mathrm{f}$ is described by Expression (3). The function in Expression (3) is described by the Moody [1] chart, Fig. (1).

$$
\begin{aligned}
& \Delta \mathrm{P}=\mathrm{fL} \rho \mathrm{V}^{2} / 2 \mathrm{gD} \ldots \\
& \mathrm{f}_{\text {laminar }}=64 / \mathrm{Re} \ldots \\
& \mathrm{f}_{\text {turbulent }}=\text { function of Re and } \varepsilon / \mathrm{D} \ldots
\end{aligned}
$$

Oftentimes, the "Darcy equation", $f$, and the Moody chart are not used, and fluid flow behavior is approximated by empirical, analytical correlations in the literature, such as,

$\Delta \mathrm{P}_{\text {turbulent }}=\mathrm{aL} \rho \mathrm{V}^{\mathrm{n}} / 2 \mathrm{gD} \ldots$

\section{HISTORICAL BACKGROUND FROM BROWN [2]}

In 1845, the fluid friction factor was presented by Weisbach [3] in the "Darcy equation", Expression (1).

In Weisbach's view, this expression was a general description of the behavior of fluids flowing in pipes. It was not accepted for some time because Weisbach "did not provide adequate data for the variation in $f$ with velocity. Thus, his equation performed poorly compared to the empirical Prony equation in wide use at the time;

$\Delta \mathrm{P}=\rho \mathrm{L} / \mathrm{D}\left(\mathrm{aV}+\mathrm{bV}^{2}\right) \ldots$

in which $\mathrm{a}$ and $\mathrm{b}$ are empirical friction factors for the velocity and velocity squared."

*Address correspondence to this author at the Ventuno Press, Green Valley, Arizona; E-mail: Efadiutori@aol.com
Darcy [4] was the first to recognize that $\Delta \mathrm{P}$ depends on wall roughness. Fanning [5] was the first to reduce fluid flow data to friction factor values that quantified the effect of both $\mathrm{V}$ and wall roughness.

(This article is an extension of the friction factor view presented in Adiutori [6].)

\section{THE "DARCY EQUATION" IS NOT AN EQUATION}

The "Darcy equation" is not an equation, even though it is written in the form of an equation. Equations describe the relationship between the parameters on the left side of the equation and those on the right side. The "Darcy equation" does not do this, and therefore it is not an equation.

For example, the "Darcy equation" does not describe the relationship between $\Delta \mathrm{P}$ and $\mathrm{V}$, even though it appears to state that $\Delta \mathrm{P}$ is proportional to $\mathrm{V}^{2}$.

The "Darcy equation" would be an equation if $f$ were a constant coefficient, in which case the equation would in fact state that $\Delta \mathrm{P}$ is proportional to $\mathrm{V}^{2}$.

\section{f IS NOT A CONSTANT COEFFICIENT}

The $f$ in the "Darcy equation" is not a constant coefficient, even though the symbolism in the "Darcy equation" indicates that $\mathrm{f}$ is a constant coefficient. $\mathrm{f}$ is a variable that depends on $\operatorname{Re}$ and $\varepsilon / \mathrm{D}$, and it should be written in the form $f\{\operatorname{Re}, \varepsilon / D\}$.

Rouse and Ince [7] state that Weisbach "found the coefficient $f$ to vary not only with the velocity ... but also with the diameter and wall material". Since Weisbach viewed the fluid friction factor as a variable that depends on $\mathrm{V}, \mathrm{D}$, and wall material, it is surprising that he presented it in 


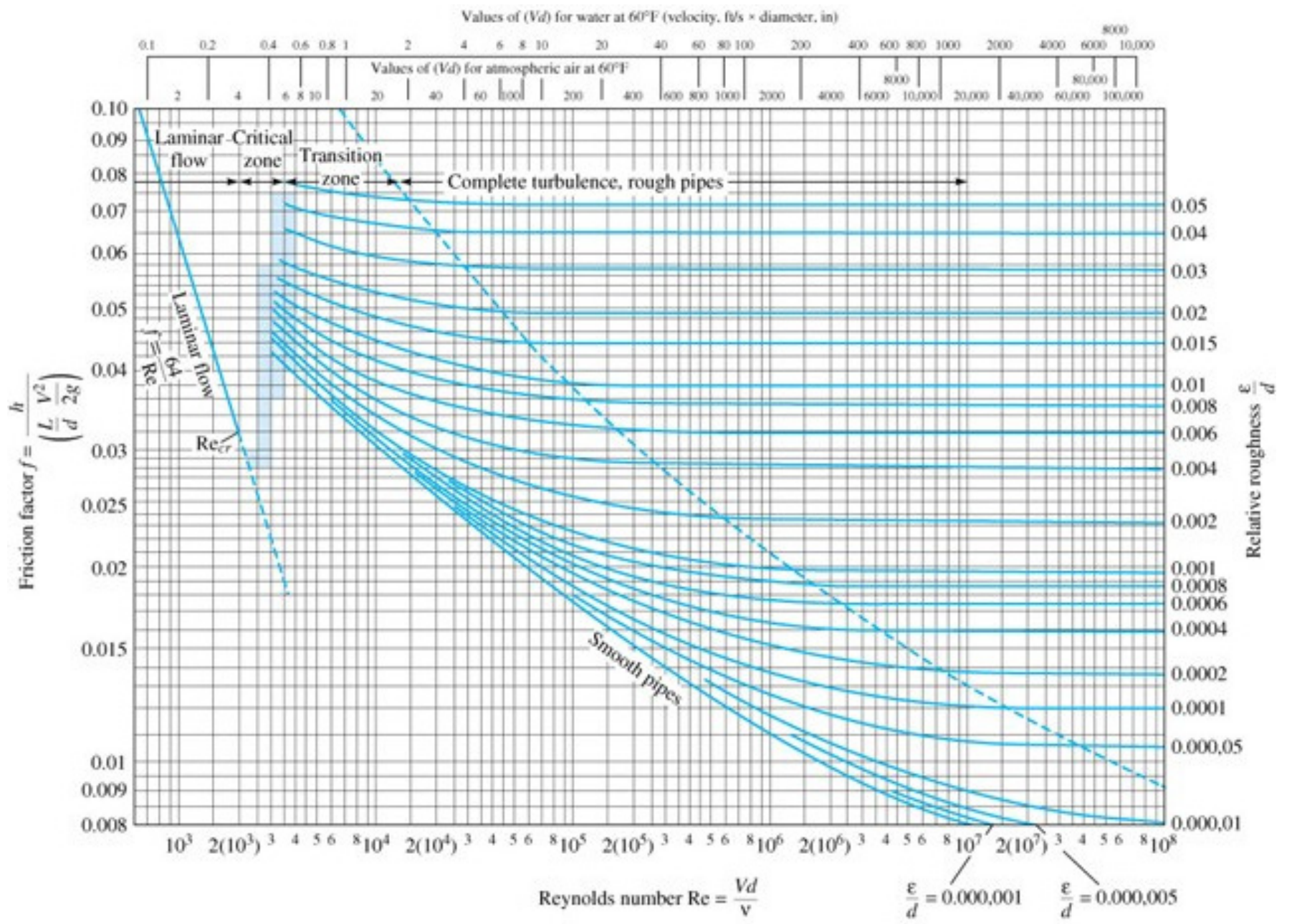

Fig. (1). The Moody [1] chart.

the form "f" rather than the correct form " $f\{\mathrm{~V}, \mathrm{D}$, wall material\}".

\section{THE "DARCY EQUATION" IS A DEFINITION}

The "Darcy equation" is a definition. It defines $\mathrm{f}$ to be $2 \Delta \mathrm{PgD} / \mathrm{L} \rho \mathrm{V}^{2}$, and should be written in the form of a definition, as in Definition (6).

$\mathrm{f} \equiv 2 \Delta \mathrm{PgD} / \mathrm{L} \rho \mathrm{V}^{2} \ldots$

\section{f IS A DIMENSIONLESS GROUP}

$\mathrm{f}$ is a dimensionless group defined by the "Darcy equation", just as Re is a dimensionless group defined by Definition (7).

$\mathrm{Re} \equiv 4 \mathrm{~W} / \pi \mu \mathrm{D} \ldots$

Dimensionless groups are best defined by independent parameters in order to readily reveal the true nature of the group. For example, Definition (6) seems to state that the $f$ group includes $\mathrm{D}$, when in fact it states that the $\mathrm{f}$ group includes $\mathrm{D}^{5}$. This seeming contradiction results because $\mathrm{V}$ is not an independent parameter in Definition (6).

Combining Definition (6) and Eq. (8) eliminates V, and results in Definition (9).

$\mathrm{V}=4 \mathrm{~W} / \pi \rho \mathrm{D}^{2} \ldots$ $\mathrm{f} \equiv \pi^{2} \mathrm{~g} \rho \Delta \mathrm{PD}^{5} / 8 \mathrm{LW}^{2} \ldots$

Definition (9) is the most desirable form of the "Darcy equation" because it reveals that the "Darcy equation" is not an equation, and because it defines $f$ in the clearest possible way.

\section{THE MODERN VIEW OF FLUID FLOW BEHAVIOR IN TERMS OF PHYSICAL PARAMETERS}

Equation (2) and Expression (3) describe the modern view of fluid flow behavior in terms of the dimensionless groups $f$ and Re. Substituting $\pi^{2} g \rho \Delta \mathrm{PD}^{5} / 8 \mathrm{LW}^{2}$ for $\mathrm{f}$ and $4 \mathrm{~W} / \pi \mu \mathrm{D}$ for Re in Eq. (2) and Expression (3) results in Eq. (10) and Expression (11), the modern view of fluid flow behavior expressed in terms of physical parameters:

$\left(\pi^{2} \mathrm{~g} \rho \Delta \mathrm{PD}^{5} / 8 \mathrm{LW}^{2}\right)_{\text {laminar }}=16 \pi \mu \mathrm{D} / \mathrm{W} \ldots$

$\left(\pi^{2} \mathrm{~g} \rho \Delta \mathrm{PD}^{5} / 8 \mathrm{LW}^{2}\right)_{\text {turbulent }}=$ function of $4 \mathrm{~W} / \pi \mu \mathrm{D}$ and $\varepsilon / \mathrm{D}$

The function in Expression (11) is described by the Moody chart.

\section{THE MOODY [1] CHART, (FIG. 1)}

The Moody chart appears in most texts and handbooks on fluid flow engineering. Moody prepared the chart by plotting widely used correlations that were applied over narrow 
ranges of Reynolds numbers, then fairing curves between the different ranges.

In terms of dimensionless groups, the Moody chart is in the form of Eq. (2) and Expression (3). In terms of physical parameters, the Moody chart is in the form of Eq. (10) and Expression (11).

Moody explained why the coordinates in the Moody chart are $f$ and Re, since other coordinates were also used to describe fluid flow behavior in 1944:

\section{R. J. S. Pigott [8] published a chart for the (Darcy friction factor), using the same coordinates (used in the Moody chart). His chart has proved to be most useful and practical and has been reproduced in a number of texts.}

\section{THE "DARCY EQUATION", f, AND THE MOODY CHART ARE SUPERFLUOUS IN THE LAMINAR REGIME}

The "Darcy equation", f, and the Moody chart are superfluous in the laminar regime because fluid flow behavior is described by Eq. (12), obtained by rearranging Eq. (10).

$\Delta \mathrm{P}_{\text {laminar }}=128 \mu \mathrm{WL} / \pi \mathrm{gD}^{4} \rho \ldots$

Note that the "Darcy equation" appears to indicate that $\Delta \mathrm{P}$ is generally proportional to $\mathrm{V}^{2}$, even though $\Delta \mathrm{P}$ is proportional to $\mathrm{V}$ in the laminar regime. The seeming contradiction results because $f$ in the "Darcy equation" is written as though it were a constant coefficient, when in fact $\mathrm{f}$ is a variable that depends on $\mathrm{Re}$ and $\varepsilon / \mathrm{D}$, and should be written in the form $f\{\operatorname{Re}, \varepsilon / D\}$.

In summary, the "Darcy equation", $f$, and the Moody chart serve no useful purpose when dealing with laminar flow.

\section{WHY I IS MATHEMATICALLY UNDESIRABLE}

$\mathrm{f}$ is the group $\pi^{2} \mathrm{~g} \rho \Delta \mathrm{PD}^{5} / 8 \mathrm{LW}^{2}$. The $\mathrm{f}$ group is mathematically undesirable because it includes $\Delta \mathrm{P}, \mathrm{W}$, and $\mathrm{D}$. This makes it necessary to solve turbulent fluid flow problems with $\Delta \mathrm{P}, \mathrm{W}$, and $\mathrm{D}$ together in $\mathrm{f}$, whereas the problems would be easier to solve if $\Delta \mathrm{P}, \mathrm{W}$, and $\mathrm{D}$ were in separate terms.

Using f methodology, turbulent fluid flow is described by Expression (11). With regard to $\Delta \mathrm{P}, \mathrm{W}$, and $\mathrm{D}$, Expression (11) is in the form of Expression (13), whereas the mathematically desirable form is Expression (14).

$\Delta \mathrm{PD}^{5} / \mathrm{W}^{2}=$ function of $\mathrm{W} / \mathrm{D}$ and $\mathrm{D} \ldots$

$\Delta \mathrm{P}=$ function of $\mathrm{W}$ and $\mathrm{D} \ldots$

In summary, $f$ is mathematically undesirable because $f$ makes it necessary to solve turbulent fluid flow problems with the variables together as in Expression (13), even though the problems would be easier to solve if the variables were separated as in Expression (14). (Just as it is generally much easier to solve equations if $\mathrm{x}$ and $\mathrm{y}$ are separated).
Using the Moody chart (Fig. 1) to solve practical problems illustrates why $\mathrm{f}$ is mathematically undesirablei.e. why $\pi^{2} \mathrm{~g} \rho \Delta \mathrm{PD}^{5} / 8 \mathrm{LW}^{2}$ is mathematically undesirable.

\section{THE MOODY CHART MUST BE READ ITERA- TIVELY TO DETERMINE W OR D}

The Moody chart must be read iteratively (or by trialand-error) to determine $\mathrm{W}$ or $\mathrm{D}$ because the chart is based on $\mathrm{f}$, a dimensionless group that includes $\Delta \mathrm{P}, \mathrm{W}$, and $\mathrm{D}$.

Note that if the chart is used to determine $W$, the coordinates of $\mathrm{f}$ and $\mathrm{Re}$ cannot be calculated from the given information because $\mathrm{f}$ and $\mathrm{Re}$ are groups that include $\mathrm{W}$. Therefore the chart must be read iteratively (or by trial-anderror).

Also note that, if the chart is used to determine D, the coordinates of $\mathrm{f}, \mathrm{Re}$, and $\varepsilon / \mathrm{D}$ cannot be calculated from the given information because $\mathrm{f}, \mathrm{Re}$, and $\varepsilon / \mathrm{D}$ are dimensionless groups that include D. Therefore the chart must be read iteratively (or by trial-and-error).

\section{HOW THE MOODY CHART CAN BE TRANSFOR- MED TO A FORM THAT IS READ WITHOUT ITERATING}

The Moody chart can be transformed to a form that is read without iterating to determine $\Delta \mathrm{P}, \mathrm{W}$, or $\mathrm{D}$. The transformation is based on noting the following:

$$
\begin{aligned}
& \mathrm{f} \equiv \pi^{2} \mathrm{~g} \rho \Delta \mathrm{PD}^{5} / 8 \mathrm{LW}^{2} \ldots \\
& \operatorname{Re} \equiv 4 \mathrm{~W} / \pi \mu \mathrm{D} \ldots \\
& \mathrm{fRe}^{2}(\varepsilon / \mathrm{D})^{3} \equiv 2 \Delta \mathrm{Pg} \rho \varepsilon^{3} / \mathrm{L} \mu^{2} \ldots \\
& \operatorname{Re}(\mathrm{D} / \varepsilon) \equiv 4 \mathrm{~W} / \pi \mu \varepsilon \ldots
\end{aligned}
$$

Identity (17) indicates that $\operatorname{fRe}^{2}(\varepsilon / D)^{3}$ includes $\Delta \mathrm{P}$, but does not include $\mathrm{W}$ or $\mathrm{D}$. Identity (18) indicates that $\mathrm{Re}(\mathrm{D} / \varepsilon)$ includes $\mathrm{W}$, but does not include $\Delta \mathrm{P}$ or $\mathrm{D}$.

Therefore $\Delta \mathrm{P}, \mathrm{W}$, and $\mathrm{D}$ are in separate terms in charts based on $\mathrm{fRe}^{2}(\varepsilon / \mathrm{D})^{3}, \operatorname{Re}(\mathrm{D} / \varepsilon)$, and $\varepsilon / \mathrm{D}$-ie charts based on $2 \Delta \mathrm{Pg} \rho \varepsilon^{3} / \mathrm{L} \mu^{2}, 4 \mathrm{~W} / \pi \mu \varepsilon$, and $\varepsilon / \mathrm{D}$. Since $\Delta \mathrm{P}, \mathrm{W}$, and $\mathrm{D}$ are separated, the charts are in the form of Expression (14), and can be read without iterating to determine $\Delta \mathrm{P}, \mathrm{W}$, or $\mathrm{D}$.

\section{THE MOODY CHART TRANSFORMED TO A FORM THAT IS READ WITHOUT ITERATING, FIG. (2)}

Fig. (2) is the Moody chart transformed to Expression (19), a form that is read without iterating.

$$
\log (\mathrm{W} / \mu \varepsilon)=\text { function of } \log (\varepsilon / \mathrm{D}) \text { and } \log \left(\Delta \mathrm{Pg} \rho \varepsilon^{3} / \mathrm{L} \mu^{2}\right)
$$

The transformation was accomplished in the following steps:

1. Obtain $\mathrm{f}, \mathrm{Re}$, and $\varepsilon / \mathrm{D}$ coordinates for eleven curves in the Moody chart by reading the chart for relative roughness from .00001 to .05 at Reynolds numbers from $10^{4}$ to $10^{8}$.

2. Use the $\mathrm{f}, \mathrm{Re}$, and $\varepsilon / \mathrm{D}$ coordinates obtained in Step 1 to calculate coordinates of $0.5 \mathrm{fRe}^{2}(\varepsilon / \mathrm{D})^{3}$ and $(\pi / 4) \mathrm{Re}$ $(\mathrm{D} / \varepsilon)$. 


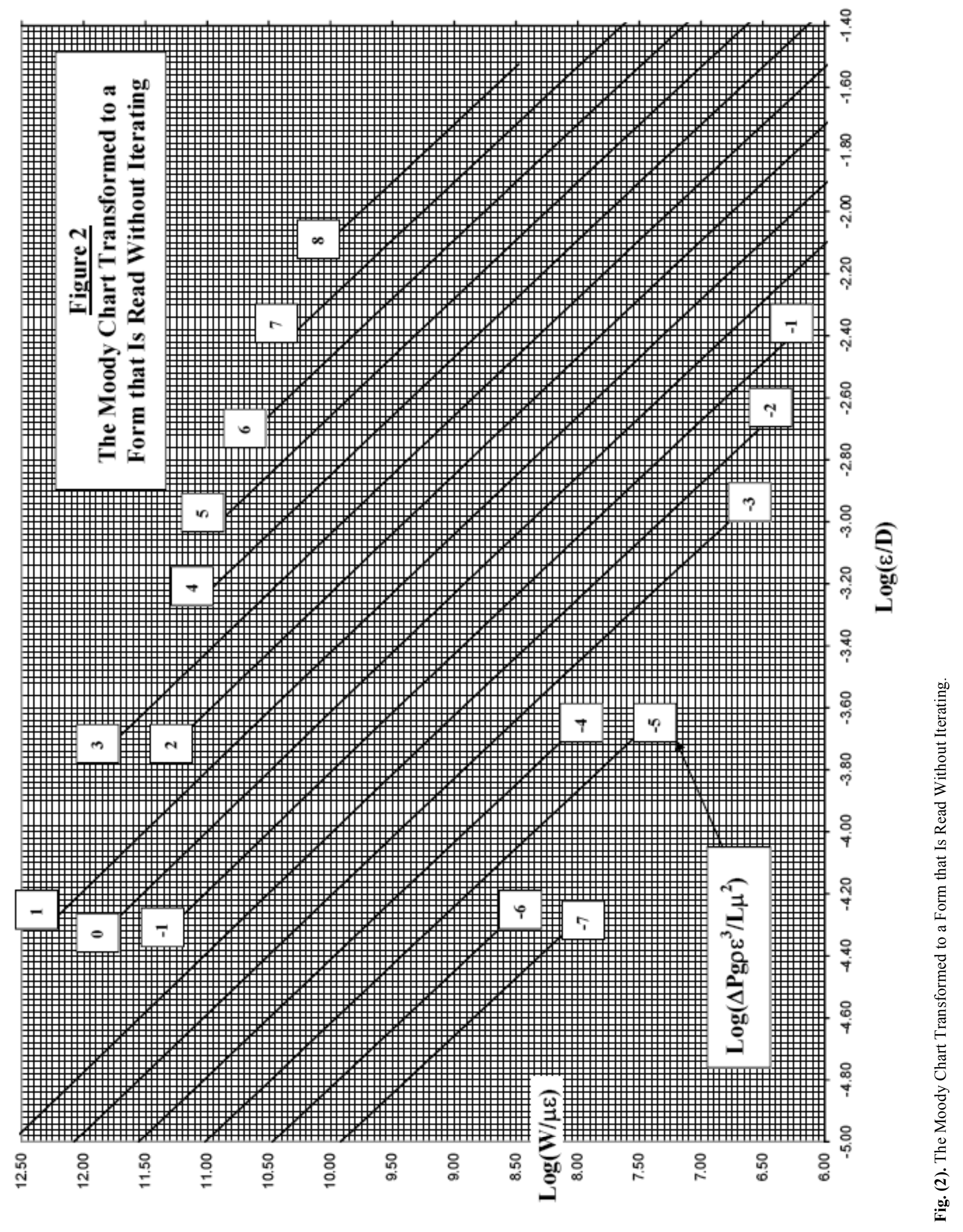


3. Use the $0.5 \mathrm{fRe}^{2}(\varepsilon / \mathrm{D})^{3}$ and $(\pi / 4) \operatorname{Re}(\mathrm{D} / \varepsilon)$ coordinates calculated in Step 2 to prepare Fig. (2), a chart of $\log ((\pi / 4) \operatorname{Re}(\mathrm{D} / \varepsilon))$ vs. $\log (\varepsilon / \mathrm{D})$, parameter $\log \left(0.5 \mathrm{fRe}^{2}\right.$ $\left.(\varepsilon / D)^{3}\right)$. Note that Fig. (2) is presented in terms of physical parameters rather than dimensionless parameters. It is labeled $\log (\mathrm{W} / \mu \varepsilon) v s . \log (\varepsilon / \mathrm{D})$, parameter $\log \left(\Delta \operatorname{Pg} \rho \varepsilon^{3} / L \mu^{2}\right)$.

Note the following in Fig. (2):

- The y coordinate is dependent on $\mathrm{W}$, but is independent of $\Delta \mathrm{P}$ and $\mathrm{D}$.

- The $\mathrm{x}$ coordinate is dependent on $\mathrm{D}$, but is independent of $\Delta \mathrm{P}$ and $\mathrm{W}$.

- The chart parameter is dependent on $\Delta \mathrm{P}$, but is independent of $\mathrm{D}$ and $\mathrm{W}$.

- If $\mathrm{W}$ is to be determined from Fig. (2), the coordinates on the $\mathrm{x}$ axis and the chart parameter are calculated from the given information, and the chart is read without iterating.

- If $\mathrm{D}$ is to be determined from Fig. (2), the coordinates on the y axis and the chart parameter are calculated from the given information, and the chart is read without iterating.

- If $\Delta \mathrm{P}$ is to be determined from Fig. (2), the coordinates on the $\mathrm{y}$ axis and the $\mathrm{x}$ axis are calculated from the given information, and the chart is read without iterating.

It is important to note that, over the range of Re and relative roughness common to both charts, the Moody chart and Fig. (2) are essentially identical. They differ only in form.

\section{THE MOODY CHART VS. FIG. (2)}

- $\quad$ The Moody chart and Fig. (2) are essentially identical except for form. They provide essentially the same answers to problems.

- The Moody chart is based on groups $\pi^{2} \mathrm{~g} \rho \Delta \mathrm{PD}^{5} /$ $8 \mathrm{LW}^{2}, \mathrm{~W} / \pi \mu \mathrm{D}$, and $\varepsilon / \mathrm{D}$. Fig. (2) is based on groups $\Delta \mathrm{Pg} \rho \varepsilon^{3} / \mathrm{L} \mu^{2}, \mathrm{~W} / \mu \varepsilon$, and $\varepsilon / \mathrm{D}$.

- $\quad$ The Moody chart must be read iteratively (or by trialand-error) when it is used to determine $\mathrm{W}$ or $\mathrm{D}$ in the turbulent regime. Fig. (2) is read without iterating when it is used to determine $\Delta \mathrm{P}, \mathrm{W}$, or $\mathrm{D}$.

- The Moody chart describes both the laminar and turbulent regimes. Fig. (2) describes only the turbulent regime because the laminar regime is described by Eq. (12).

- $\quad$ The imprecision in reading Fig. (2) is one-fourth of a division. The resulting imprecision is $\pm 1.2 \%$ of $\mathrm{D}$, $\pm 3 \%$ of $\mathrm{W}$, and $\pm 6 \%$ of $\Delta \mathrm{P}$. The imprecision in reading a Moody chart of the same size is considerably smaller.
EXAMPLE PROBLEM USING THE MOODY CHART, FIG. (1)

A pipe line is to be laid to transport fluid from Plant A to Plant B. Using the given information and the Moody chart (Fig. 1), determine the pipe diameter that will result in a flow rate of $2.50 \mathrm{~kg} / \mathrm{s}$ with a pressure drop of $20000 \mathrm{~kg} / \mathrm{m}^{2}$.

\section{Given}

Pipe roughness $\varepsilon=.000050 \mathrm{~m}$

Equivalent length of pipe line $=60 \mathrm{~m}$

$\mu=.000750 \mathrm{Kg} / \mathrm{m} \mathrm{s}$

$\rho=950 \mathrm{~kg} / \mathrm{m}^{3}$

\section{Analysis}

(The analysis is to be performed by the reader.)

\section{Answer}

A pipe diameter of $.0331 \mathrm{~m}$ will result in a flow rate of $2.5 \mathrm{~kg} / \mathrm{s}$ with a pressure drop of $20000 \mathrm{~kg} / \mathrm{m}^{2}$.

\section{EXAMPLE PROBLEM USING FIG. (2)} (1).

Repeat the above problem using Fig. (2) instead of Fig.

\section{Analysis}

Use the given information to calculate values for the $y$ coordinate and the chart parameter in Fig. (2).

$\log (\mathrm{W} / \mu \varepsilon)=\log (2.5 /(.00075 \times .00005)=7.82$

$\log \left(\Delta \operatorname{Pg} \rho \varepsilon^{3} / \mathrm{L}^{2}\right)=$

$\log \left(20000 \times 9.82 \times 950 \times .00005^{3} /\left(60 x .00075^{2}\right)\right)=-.16$

Use the above values and Fig. (2) to determine the value of the $\mathrm{x}$ coordinate. Then solve for the value of $\mathrm{D}$.

$$
\begin{aligned}
& \log (\varepsilon / D)=-2.82(\text { from Fig. }(2)) \ldots \\
& \therefore(\varepsilon / D)=.00151 \ldots \\
& D=\varepsilon /(\varepsilon / D)=.00005 / .00151=.0331 \mathrm{~m} \ldots
\end{aligned}
$$

\section{Answer}

A pipe diameter of $.0331 \mathrm{~m}$ will result in a flow rate of $2.50 \mathrm{~kg} / \mathrm{s}$ with a pressure drop of $20000 \mathrm{~kg} / \mathrm{m}^{2}$.

(The Moody chart solution obtained by iterating is:

$$
\mathrm{D}=.0328 \mathrm{~m}, \mathrm{f}=.0232, \mathrm{Re}=1.29 \times 10^{5}, \varepsilon / \mathrm{D}=.00152 \text {.) }
$$

\section{HOW FLUID FLOW BEHAVIOR IS DESCRIBED WHEN F IS ABANDONED}

When $\mathrm{f}$ is abandoned, fluid flow behavior is described by $\Delta \mathrm{P}_{\text {laminar }}=128 \mu \mathrm{WL} / \pi \mathrm{gD}^{4} \rho \ldots$ (12) 
$\left(\Delta \mathrm{Pg} \rho \varepsilon^{3} / \mathrm{L} \mu^{2}\right)_{\text {turbulent }}=$ function of $\mathrm{W} / \mu \varepsilon$ and $\varepsilon / \mathrm{D}$

The function in Expression (25) is obtained by transforming the Moody chart in the manner described above.

Note that Eq. (12) is used currently, but is usually written in the friction factor form of Eq. (2). Also note that Expression (25) can be rearranged, as in Expression (19).

Expression (25) replaces Expression (11) used in $\mathrm{f}$ methodology. The particular advantage of Expression (25) is that $\Delta \mathrm{P}, \mathrm{W}$, and $\mathrm{D}$ are in separate terms, whereas $\Delta \mathrm{P}, \mathrm{W}$, and $\mathrm{D}$ are together in the $\mathrm{f}$ group in Expression (11). Separating $\Delta \mathrm{P}, \mathrm{W}$, and $\mathrm{D}$ makes it possible to solve fluid flow problems in the simplest possible manner, as illustrated above.

\section{CONCLUSIONS}

- $\quad \mathrm{f}$ is mathematically undesirable because it includes $\Delta \mathrm{P}, \mathrm{W}$, and $\mathrm{D}$. This makes it necessary to solve problems with $\Delta \mathrm{P}, \mathrm{W}$, and $\mathrm{D}$ in the same term, whereas problems are easier to solve if $\Delta \mathrm{P}, \mathrm{W}$, and $\mathrm{D}$ appear only in different terms.

- The "Darcy equation", $f$, and the current form of the Moody chart should be abandoned because $f$ is superfluous in the laminar regime, and because $\mathrm{f}$ complicates the solution of turbulent fluid flow problems.

- In the laminar regime, fluid flow behavior should be described by Eq. (12). This equation is used currently, but is often written in the friction factor form of Eq. (2).

- In the turbulent regime, fluid flow behavior should be described by a chart based on $\Delta \operatorname{Pg} \rho \varepsilon^{3} / \mathrm{L} \mu^{2}, \mathrm{~W} / \mu \varepsilon$ and $\varepsilon / D$, such as Fig. (2). The chart is obtained by transforming the Moody chart as described above.

\section{NOMENCLATURE}

$\mathrm{a}=$ An arbitrary constant
$\mathrm{b}=$ An arbitrary constant
$\mathrm{D}=$ Pipe diameter
$\mathrm{f}=$ Fluid friction factor, $\pi^{2} \mathrm{~g} \rho \Delta \mathrm{PD}^{5} / 8 \mathrm{LW}^{2}$
$\mathrm{~g}=$ Gravity constant
$\mathrm{L}=$ Length
$\mathrm{n}=$ An arbitrary constant
$\mathrm{P}=$ Pressure
$\mathrm{Re}=$ Reynolds number, $4 \mathrm{~W} / \pi \mu \mathrm{D}$
$\mathrm{V}=$ Velocity
$\mathrm{W}=$ Mass flow rate
$\varepsilon=$ Surface roughness
$\mu=$ Viscosity
$\rho=$ Density

\section{REFERENCES}

[1] L. F. Moody, "Friction factors for pipe flow", Transactions of the ASME, vol. 66, pp. 671-684, Nov 1944.

[2] G. Brown, "The history of the Darcy-Weisbach equation", 2002, Available from:

http://biosystems.okstate.edu/darcy/DarcyWeisbach/DarcyWeisbachHistory.html

[3] J. Weisbach, Lehrbuch der Ingenieur und Maschinen-Mechanik, Braunschwieg, Germany: Vieweg und Sohn, 1845.

[4] H. Darcy, "Experimental research relating to the movement of water in pipes", in Recherches Experimentales Relatives au Mouvement de L'Eau deans les Tuyaux, Paris: Mallet-Bachelier, 1857.

[5] J. T. Fanning, A Practicle Treasite on Water Supply Engineering, New York: Van Nostrand, 1877

[6] E. F. Adiutori, in The New Engineering, USA: Ventuno Press 2002 , pp. 192-194.

[7] H. Rouse and S. Ince, History of Hydraulics, Iowa city, IA: Iowa Institute of Hydraulic Research, 1957.

[8] R. J. S. Pigott, "The flow of fluids in closed conduits", Mechanical Engineering, vol. 55, pp. 497-501, 515, 1933. 